\title{
Emissions and Fuel Consumption Modeling for Evaluating Environmental Effectiveness of ITS Strategies
}

\author{
Yuan-yuan Song, ${ }^{1,2}$ En-jian Yao, ${ }^{1,2}$ Ting Zuo, ${ }^{1}$ and Zhi-feng Lang ${ }^{1}$ \\ ${ }^{1}$ State Key Laboratory of Rail Traffic Control and Safety, Beijing Jiaotong University, Beijing 100044, China \\ ${ }^{2}$ MOE Key Laboratory for Urban Transportation Complex Systems Theory and Technology, Beijing Jiaotong University, \\ Beijing 100044, China
}

Correspondence should be addressed to Yuan-yuan Song; 11120986@bjtu.edu.cn

Received 8 September 2012; Revised 14 December 2012; Accepted 15 December 2012

Academic Editor: Wuhong Wang

Copyright (c) 2013 Yuan-yuan Song et al. This is an open access article distributed under the Creative Commons Attribution License, which permits unrestricted use, distribution, and reproduction in any medium, provided the original work is properly cited.

\begin{abstract}
Road transportation is a major fuel consumer and greenhouse gas emitter. Recently, the intelligent transportation systems (ITSs) technologies, which can improve traffic flow and safety, have been developed to reduce the fuel consumption and vehicle emissions. Emission and fuel consumption estimation models play a key role in the evaluation of ITS technologies. Based on the influence analysis of driving parameters on vehicle emissions, this paper establishes a set of mesoscopic vehicle emission and fuel consumption models using the real-world vehicle operation and emission data. The results demonstrate that these models are more appropriate to evaluate the environmental effectiveness of ITS strategies with enough estimation accuracy.
\end{abstract}

\section{Introduction}

Transportation sector has been facing an increasing environmental pressure due to the rapid motorization in China over the recent years. Low-carbon transportation solutions such as substitution of fossil oil by alternative fuels, enhancing vehicle technology, and developing public transport systems have been applied widely. An alternative and promising solution is the implementation of ITS that can smooth the traffic flow and reduce congestion. In addition to the common effects, increasing attention has been paid to the indirect effect of ITS technologies on reducing the fuel consumption and $\mathrm{CO}_{2}$ emissions. Many researches have demonstrated the environmental improvement of ITS technologies $[1,2]$ especially in car navigation systems including Ecodriving $[3,4]$ and Ecorouting $[5,6]$. Therefore, it is of significance to establish emission estimation models to evaluate the environmental effectiveness of ITS strategies with enough estimation accuracy.

Vehicle emission estimation models play a critical role for regional planning and development of emission control strategies [7]. Three general approaches are usually considered in modeling vehicle emissions and fuel consumption [8]. Macroscopic models use average aggregate network parameters to estimate emission inventories for large regional areas according to the relationships between speed, flow, and density of a stream. Examples of macroscopic models applicable to vehicles include the U.S. federal's MOBILE6 [9] and California's EMFAC [10]. But these models are not well suited for evaluating traffic operational improvements that can be achieved through the ITS strategies [7]. Microscopic models such as VT-Micro model [11] and CMEM [12] model estimate instantaneous vehicle emission rates using either vehicle engine or vehicle speed/acceleration data. However, it is difficult to obtain substantial amounts of microscopic parameters for evaluating the environmental effectiveness of ITS strategies. Most existing road surveillance systems such as loop, remote traffic microwave sensor (RTMS), and floating car data (FCD) system, can readily acquire average link travel speed or point speed data. Given that macroscopic models ignore the transient variation of vehicle emissions associated with different traffic conditions, while microscopic emission estimation tools need numerous input data, it is more appropriate to utilize link-based mesoscopic emission 
models for evaluating the environmental impacts of local ITS strategies.

There are many new approaches including MOVES to estimating the emissions with an attempt to replace existing emission models such as MOBILE [13]. MOVES incorporates the concept of vehicle specific power (VSP) and characterizes vehicle activities according to VSP and speed. VSP is defined as the instantaneous power per unit mass of the vehicle, and many studies have found methods based on VSP more accurate to estimate vehicle fuel consumption and emissions. The VSP-based methods were further developed and better accepted by other researchers in the area of emission and fuel consumption modeling [14] after its first application [15]. The ability of VSP-based emission models to reflect the transient emission rates under different operating modes as well as the better estimation of vehicle emissions than speed-based emission models makes it widely utilized. In order to evaluate the effects of traffic management on fuel efficiency, Song et al. [16] developed a practical model that aggregated the normalized fuel rate under different VSP bins. Wang and colleagues [17] established a model based on VSP and speed, which provided insight that how different levels of cruise speed and acceleration affect vehicle fuel consumption. Furthermore, the accuracy was improved with prediction errors within $20 \%$ for trip emissions and linkspeed-based emission factors through follow-up studies [18]. Scora et al. [19] combined real-time traffic data along with the comprehensive modal emission models (CMEM and EPA's MOVES) to estimate the environmental measures in real time. The estimation methodology provided far more dynamic and accurate environmental information compared to static emission models.

In order to improve both the applicability and accuracy of the evaluation effect, link-based emission and fuel consumption models are necessary along with consideration of transient vehicle behavior in these models. Also, mesoscopic driving parameters collected by probe vehicle systems are well applied in some ITS strategies such as advanced traffic monitoring and management systems [20] and navigation systems $[5,6,21]$. Many existing studies have focused on vehicle emission estimation and fuel consumption models, some of which have been applied for evaluation of environmental effects [8]. However, the existing evaluation is generally realized through direct application of regulation and test procedures for fuel economy of automobiles, and the indicator is fuel consumed per unit distance such as per $100 \mathrm{~km}$ other than realistic operational modes. The input data of these models are generally average speed of a whole trip or a period time such as one hour, and the time ranges are too wide to take full advantage of the probe vehicle technology or other traffic information systems. Therefore, the primary objective of this paper is to develop practical emission and fuel consumption estimation models for evaluation of the environmental effectiveness of ITS strategies for improving regional traffic flow.

In Section 1 of the paper, background information on emissions and fuel consumption modeling for evaluating environmental effectiveness of ITS strategies is provided, along with a review of exiting studies on emission and fuel consumption models. Section 2 outlines the overall methodology of the research, and the results of emissions and fuel consumption models are illustrated. These models for evaluating environmental effectiveness of ITS strategies (i.e., ecological route navigation) are applied in Section 3. Conclusions and future work are then provided in Section 4.

\section{Model Estimation}

Light-duty vehicles and heavy-duty vehicles account for most of the vehicle fleet in the city. ITS strategies are more widely applied in these types of vehicles. Therefore, based on the emission data collected by Portable Emission Measurement System (PEMS), mesoscopic models for light-duty gasoline vehicles and heavy-duty diesel vehicles are established in this paper. In order to evaluate the environmental effectiveness of ITS strategies that can smooth the regional traffic flow, the established vehicle emission and fuel consumption models utilize average link speed as explanatory variables. Also, the VSP distribution for each travel speed level is considered as a bridge between the instantaneous driving parameters such as vehicle speed, acceleration and average link speed, which guarantees the estimation accuracy and applicability of the models. The methodology of estimation models is listed in the following sections.

2.1. Source of Data. We use the data collected by vehicle with PEMS in Beijing urban areas in this study. The vehicles were operated on regular routes in the urban area under different driving conditions (i.e., different road grades and different traffic status). The driving conditions are different with speed from 0 to $100 \mathrm{~km} / \mathrm{h}$ associated with acceleration ranging from $-5 \mathrm{~m} / \mathrm{s}^{2}$ to $5 \mathrm{~m} / \mathrm{s}^{2}$, while the corresponding VSP calculated using second-by-second data is between $-30 \mathrm{kw} / \mathrm{t}$ and $25 \mathrm{kw} / \mathrm{t}$.

2.2. Model Methodology. VSP integrates the vehicle speed, vehicle acceleration, road grade, aerodynamic drag, and tire rolling resistance, and it is generally defined as the instantaneous power per unit mass of the vehicle [22]. In this paper, simplified formulas are used to calculate the values of VSP for different types of vehicles. The following simplified function [15] in (1) is used for the VSP calculations of lightduty gasoline vehicles while heavy-duty diesel vehicle's VSP can be calculated using (2) according to the existing research results [23]:

$$
\begin{gathered}
\mathrm{VSP}=v \times(1.1 \times a+0.132)+0.000302 \times v^{3}, \\
\mathrm{VSP}=v \times(a+0.09199)+0.000169 \times v^{3},
\end{gathered}
$$

where $v$ and $a$ are the vehicle speed and acceleration in $\mathrm{m} / \mathrm{s}$ and $\mathrm{m} / \mathrm{s}^{2}$, respectively.

For the characteristics of vehicle emission change greatly under different travel conditions, VSP is separated as a bin with an equal interval of $1 \mathrm{kw} / \mathrm{t}$, as described in

$$
\forall: \operatorname{VSP} \in[n, n+1), \quad \text { VSP } \text { bin }=n, n \text { is integer. }
$$


Each VSP bin is associated with average emission rates for different types of emissions, respectively. The second-bysecond data collected by PEMS is divided into traveling fragment by different time interval and the optimal time granularity is discussed in the following section. Each fragment is characterized with its average speed that is as the basis of division of fragments. After the interval division of average speed, the VSP-Bin distribution attribute of each average speed range is calculated. The average emission rate under each average speed range is estimated as

$$
\overline{\mathrm{ER}}_{i}=\sum_{j} E R_{j} \times \frac{t_{i, j}}{T_{i}},
$$

where $\overline{E R}_{i}$ is the average emission rate under average speed range $i, \mathrm{~g} / \mathrm{s} ; j$ is the index of VSP bin; $E R_{j}$ is the emission rate for VSP bin $j, \mathrm{~g} / \mathrm{s} ; t_{i, j}$ is the time spent in VSP bin $j$ on speed range $i, \mathrm{~s}$; and $T_{i}$ is the total travel time under speed range $i$, s.

The instantaneous fuel consumption is calculated from emissions of $\mathrm{CO}_{2}, \mathrm{HC}$, and $\mathrm{CO}$ using carbon balance method listed in national standards of China [24]. Vehicle fuel consumption rates for gasoline vehicles and diesel vehicles can be estimated using (5) and (6), respectively, as follows:

$$
\begin{aligned}
& F R_{\mathrm{S}}=1.154 \times\left(E R_{\mathrm{HC}} \times \frac{12}{13}+E R_{\mathrm{CO}} \times \frac{12}{28}+E R_{\mathrm{CO}_{2}} \times \frac{12}{44}\right), \\
& F R_{C}=1.155 \times\left(E R_{\mathrm{HC}} \times \frac{12}{13}+E R_{\mathrm{CO}} \times \frac{12}{28}+E R_{\mathrm{CO}_{2}} \times \frac{12}{44}\right),
\end{aligned}
$$

where $F R_{S}$ and $F R_{C}$ are the fuel consumption rates of gasoline vehicles and diesel vehicles, respectively, g/s; $E R_{\mathrm{HC}}, E R_{\mathrm{CO}}$, and $E R_{\mathrm{CO}_{2}}$ are the $\mathrm{HC}, \mathrm{CO}$, and $\mathrm{CO}_{2}$ emission rates, respectively, $\mathrm{g} / \mathrm{s}$.

Then the emission/fuel consumption factor under each average speed range is estimated as:

$$
\begin{gathered}
V_{l}=\frac{\sum_{k=1}^{n} D_{k}}{\sum_{k=1}^{n} T_{k}}, \\
E F_{l}\left(F F_{l}\right)=E R_{i}\left(F R_{i}\right) \times \frac{\sum_{k=1}^{n} T_{k}}{\sum_{k=1}^{n} D_{k}},
\end{gathered}
$$

where $T_{k}$ is the vehicle trip time spent in the travel fragment $k$ of average speed range $i, s ; D_{k}$ is the vehicle trip distance in travel fragment $k$ of average speed range $i, \mathrm{~km} ; V_{l}$ is the vehicle travel speed for average speed range $i, \mathrm{~km} / \mathrm{h} ; E R_{i}\left(F R_{i}\right)$ is the emission (fuel consumption) rate for average speed range $i$, $\mathrm{g} / \mathrm{s}$; and $E F_{l}\left(F F_{l}\right)$ is the emission (fuel consumption) factor for $V_{l}$.

Based on the previous research [25] and the relationship of emission (fuel consumption) factors versus average speed, (8) is used as the fitted formula between vehicle emission (fuel consumption) factor s and average speed:

$$
E F(F F)=\frac{a}{v}+b+c v+d v^{2}
$$

where $E F(F F)$ is the emission (fuel consumption) factor, $\mathrm{g} / \mathrm{km} ; v$ is average speed, $\mathrm{km} / \mathrm{h} ; a, b, c$, and $d$ are coefficients.
2.3. Estimation Results. Figure 1 shows the similar characteristic of various vehicle emission and fuel consumption rates for light-duty and heavy-duty as VSP changes and a VSP of $0 \mathrm{~kW} / \mathrm{t}$ is the inflection point. When the VSP value is positive, emission and fuel consumption rates indicate a rapid increase with the increase of VSP. Emission and fuel consumption rates tend to be very low and almost invariable for negative VSP.

The emission and fuel consumption rates of two types of vehicles are illustrated in Figure 2. As illustrated in Figure 2, the emission and fuel consumption rates typically increase with the increment of average speed. It should be noted that there is an apparent increase for emission and fuel consumption rates during the lower average speed range, while the rates rise relatively slowly when the speed increase to a specific value.

The emission and fuel consumption models have been established based on the proposed approach. As the traveling fragment by different time interval has effects on the model precision and estimation errors. It is valuable to explore the least estimation error and discuss the optimal time granularity. Successive 600-secong-long measurement trips for different time granularities were used for validation. The errors between the modeled and measured trip emissions and fuel consumption are shown in Table 1.

Table 1 illustrated that the modeled and measured emission and fuel consumption rates for light-duty vehicle under different time granularities are in good agreement, and all the differences between them are within $10 \%$. Moreover, the time granularity has a less significant effect on the estimation errors. The optimal time granularity can be regarded as 60 second.

The vehicle emission and fuel consumption factor curves and estimation models for both vehicle types are shown in Figure 3 and Table 2 when the time granularity is 60 second.

Figure 3 illustrates that the changing tendencies for all vehicle emission curves are consistent with the exiting research results [11, 26, 27]: vehicle emission factors decrease as speed increases to a specified value, and then start to increase. Noteworthy is the fact that the values of the emission and fuel consumption factors drop dramatically at a lower average speed. For example, for light-duty vehicle, the value of $\mathrm{CO}_{2}$ emission per kilometer declines greatly with the increase of speed, once the speed reaches to about $65 \mathrm{~km} / \mathrm{h}$, the value of $\mathrm{CO}_{2}$ emission per kilometer will increase slowly. The optimal average speed is approximately $65 \mathrm{~km} / \mathrm{h}$ with the minimum $\mathrm{CO}_{2}$ emission rate of $210 \mathrm{~g} / \mathrm{km}$.

\section{Application}

Many ITS strategies have indirect influence on reducing emissions and fuel consumption through standardizing driving behavior, smoothing road traffic flow, and improving commuting efficiency. For example, the technology of traffic control in merging areas can provide a proper merging speed and opportunity for vehicles, which leads to improvement of 
TABLE 1: Comparison of emission and fuel consumption rates from modeled and measured values.

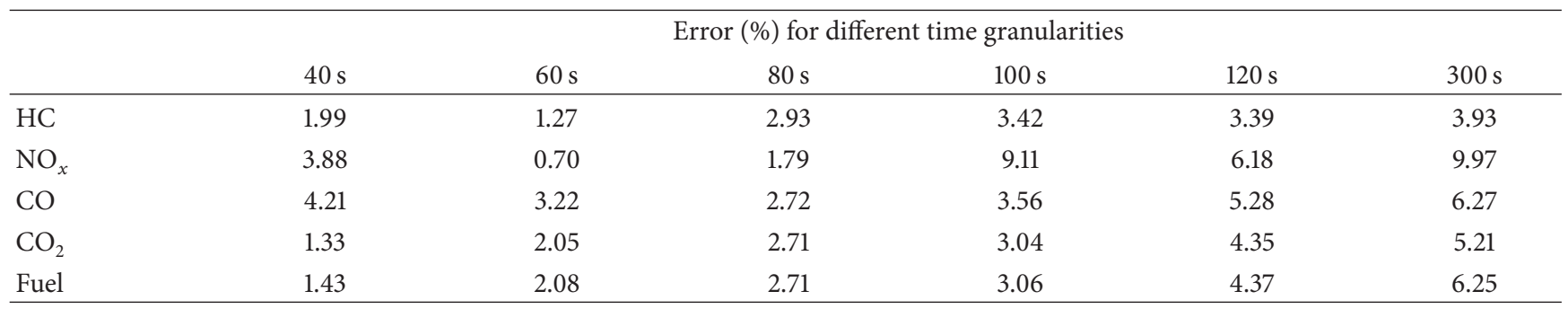

TABLE 2: Vehicle emission and fuel consumption factor models.

\begin{tabular}{ll}
\hline Vehicle type & Estimation models \\
\hline & $E F_{\mathrm{HC}}=1.08 \times 10^{1} \times V^{-1}-7.11 \times 10^{-3}+3.76 \times 10^{-4} \times V+3.63 \times 10^{-5} \times V^{2}, R^{2}=0.91$ \\
& $E F_{\mathrm{NO}_{x}}=2.00 \times V^{-1}-4.49 \times 10^{-2}-3.36 \times 10^{-4} \times V+3.49 \times 10^{-5} \times V^{2}, R^{2}=0.87$ \\
& $E F_{\mathrm{CO}}=8.08 \times 10^{1} \times V^{-1}+1.16+5.03 \times 10^{-3} \times V+5.35 \times 10^{-4} \times V^{2}, R^{2}=0.94$ \\
& $E F_{\mathrm{CO}_{2}}=4.78 \times 10^{3} \times V^{-1}+1.11 \times 10^{2}-1.24 \times V+2.37 \times 10^{-2} \times V^{2}, R^{2}=0.95$ \\
& $F F^{2}=1.56 \times 10^{2} \times V^{-1}+3.54-3.88 \times 10^{-2} \times V+7.76 \times 10^{-4} \times V^{2}, R^{2}=0.95$ \\
\hline & $E F_{\mathrm{HC}}=1.55 \times 10^{1} \times V^{-1}+3.92 \times 10^{-1}-7.20 \times 10^{-3} \times V+5.31 \times 10^{-5} \times V^{2}, R^{2}=0.98$ \\
& $E F_{\mathrm{NO}_{x}}=8.91 \times 10^{1} \times V^{-1}+9.35-1.36 \times 10^{-1} \times V+8.91 \times 10^{-4} \times V^{2}, R^{2}=0.98$ \\
& $E F_{\mathrm{CO}}=4.14 \times 10^{1} \times V^{-1}+1.99-1.10 \times 10^{-2} \times V+2.99 \times 10^{-5} \times V^{2}, R^{2}=0.99$ \\
& $E F_{\mathrm{CO}_{2}}=3.67 \times 10^{3} \times V^{-1}+5.34 \times 10^{2}-7.90 \times V+5.43 \times 10^{-2} \times V^{2}, R^{2}=0.99$ \\
& $F F^{\text {Heavy duty vehicles }}=1.19 \times 10^{2} \times V^{-1}+1.69 \times 10^{1}-2.50 \times 10^{-1} \times V+1.72 \times 10^{-3} \times V^{2}, R^{2}=0.99$ \\
&
\end{tabular}

Note: $E F$ is the emission factor, $\mathrm{g} / \mathrm{km} ; F F$ is the fuel consumption factor, $\mathrm{g} / \mathrm{km} ; V$ is average speed, $\mathrm{km} / \mathrm{h}$.

travel speed for upstream traffic flow. The proposed vehicle emission and fuel consumption factor models are described as functions of average link speed that can be collected by most existing road traffic information systems such as loopcoil detectors. Further, the effectiveness of emission and fuel consumption reduction utilizing the technology of traffic control can be evaluated through these emission and fuel consumption models. Moreover, the models developed in this study are incorporated into an ecological route navigation system to further demonstrate their applicability to ITS strategies.

The studying area is located in central area of Beijing. Based on the route planning algorithm, the ecological route navigation system consists of a dynamic traffic information database, emissions/fuel estimation models and user interfaces, which can provide vehicle the least emissions or fuel. The dynamic traffic information database is collected from a probe vehicle system, which provides travel time for each link every five intervals. It means only average travel speed of each link can be obtained and used for the ecological route navigation.

Figure 4 illustrates the route navigation results of the ecological route compared with the time priority route for the specified OD pair. It is obvious that ecological route is different from the time priority route. Based on the proposed emissions and fuel consumption models, the comparison results between the two routes are summarized in Table 3 . Values in the table are normalized to the time priority route's results. The fuel consumption of the ecological route is about $13.5 \%$ lower than that of the time priority route, although the travel time of the ecological route is just about $1.2 \%$ longer. Noteworthy is the fact that the value of the fuel consumption reduction is extremely similar in the appearance to the $\mathrm{CO}_{2}$ reduction. This result verifies that estimation models can be utilized to calculate the emissions and fuel consumption during the whole trip and evaluate the environmental effect on emissions and fuel consumption reduction.

\section{Conclusions}

The paper presents a methodology for establishing mesoscopic emission and fuel consumption models for assessing the environmental impacts of ITS strategies. The proposed models are developed through considering the influence of the vehicle's operating mode on vehicle emissions, which not only guarantees the accuracy of emissions and fuel consumption models, but also makes it possible to estimate the emission and fuel consumption based on most current traffic information systems. With more and more PEMS data for specific vehicles are obtained in the future, the models for other types of vehicles can be estimated and the emissions inventory is expected to be accomplished. Furthermore, it is verified that these models are well applied to evaluate the effect of ITS technologies on reducing vehicle emissions and fuel consumption. 
TABLE 3: Results of evaluation of ecological route strategy.

\begin{tabular}{lccc}
\hline & Ecological route & Time-priority route & \% Differences \\
\hline Travel distance $(\mathrm{km})$ & 13.3 & 16.2 & $-17.9 \%$ \\
Travel time $(\mathrm{min})$ & 17.6 & 17.4 & $1.2 \%$ \\
$\mathrm{CO}_{2}$ emission $(\mathrm{kg})$ & 3.2 & 3.6 & $-13.5 \%$ \\
Fuel consumption $(\mathrm{kg})$ & 1.0 & 1.2 & $-13.5 \%$ \\
\hline
\end{tabular}

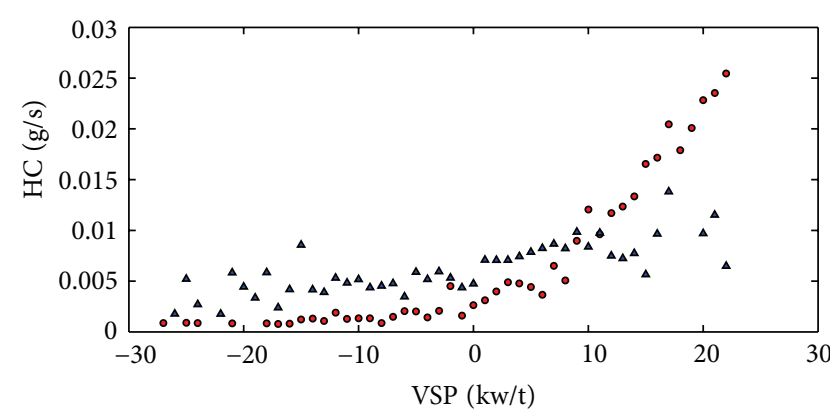

- Light-duty vehicle

$\Delta$ Heavy-duty vehicle

(a)

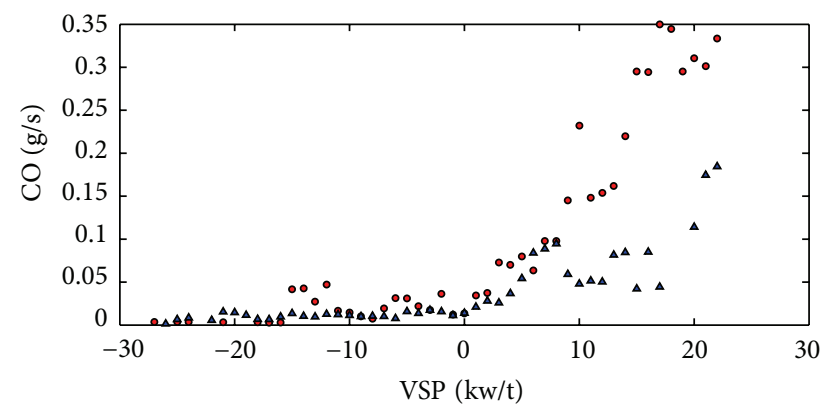

- Light-duty vehicle

$\Delta$ Heavy-duty vehicle

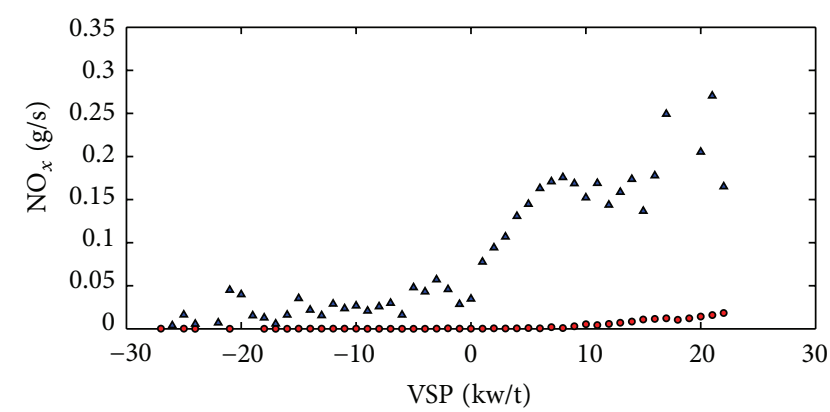

- Light-duty vehicle

$\Delta$ Heavy-duty vehicle

(b)

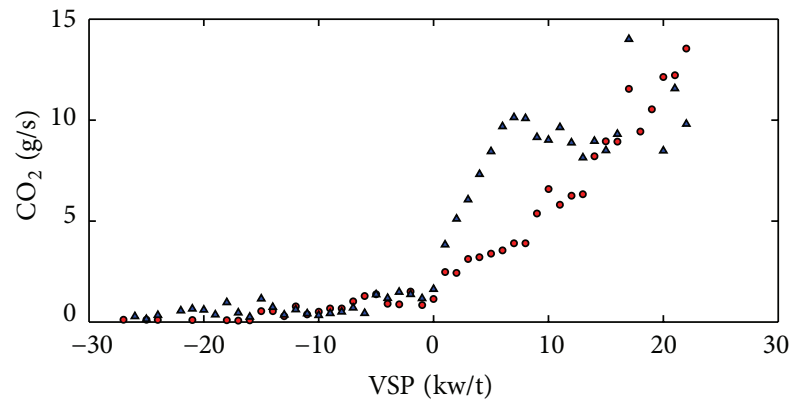

- Light-duty vehicle

$\Delta$ Heavy-duty vehicle

(d)

(c)

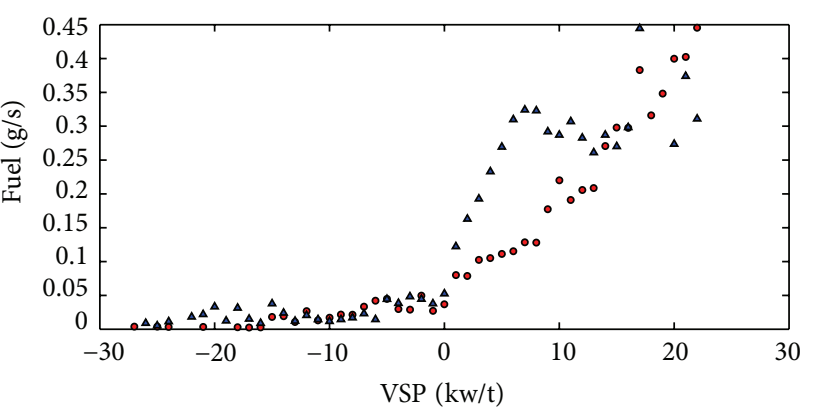

- Light-duty vehicle

$\Delta$ Heavy-duty vehicle

(e)

FIGURE 1: Emission and fuel consumption rates under different VSP-bins (Light- and heavy-duty vehicle). 


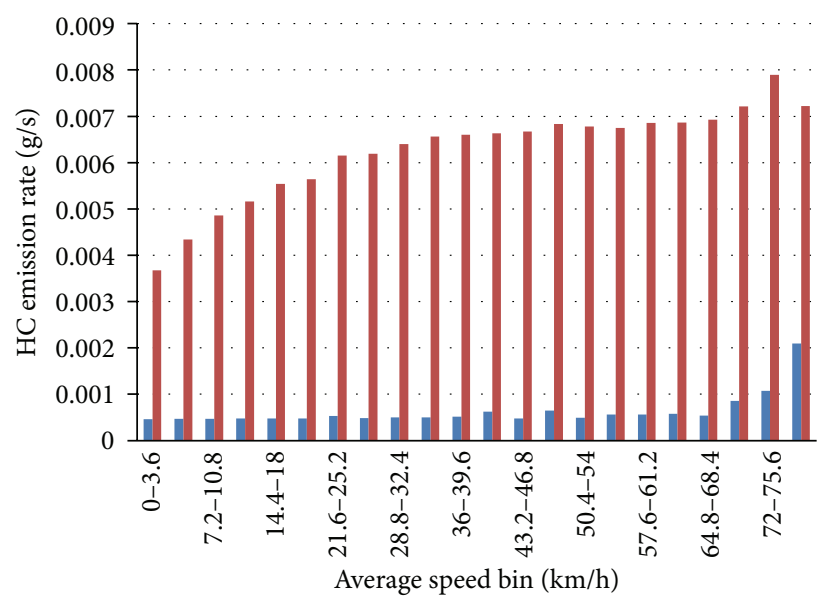

- Light-duty gasoline vehicle

- Heavy-duty diesel vehicle

(a)

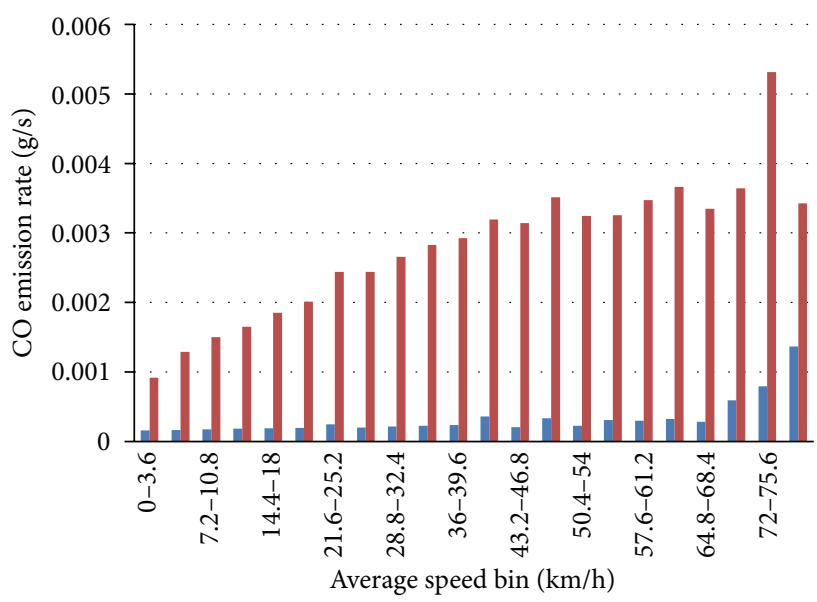

- Light-duty gasoline vehicle

- Heavy-duty diesel vehicle

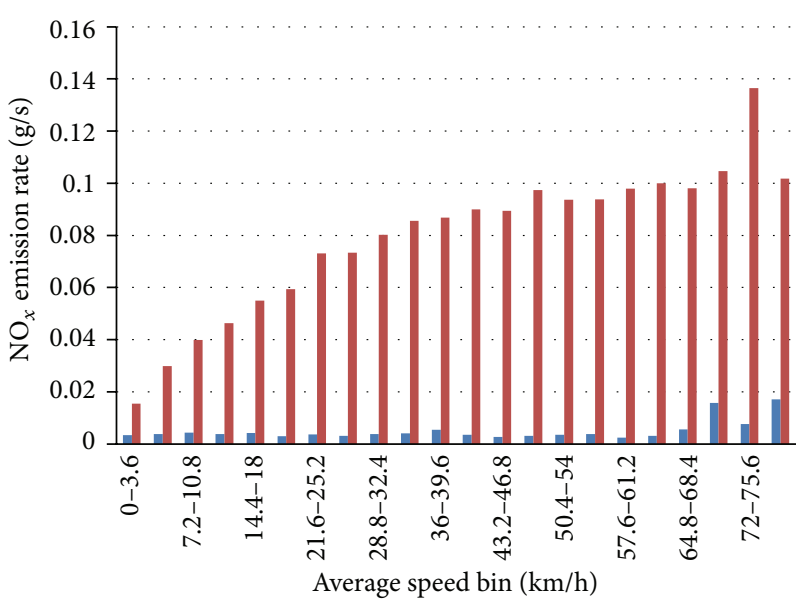

- Light-duty gasoline vehicle $* 10$

- Heavy-duty diesel vehicle

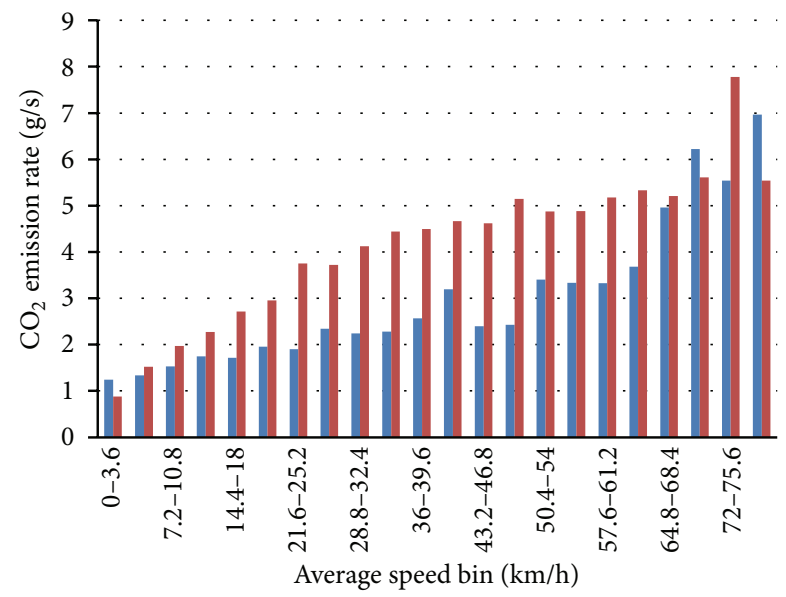

- Light-duty gasoline vehicle

- Heavy-duty diesel vehicle

(d)

(c)

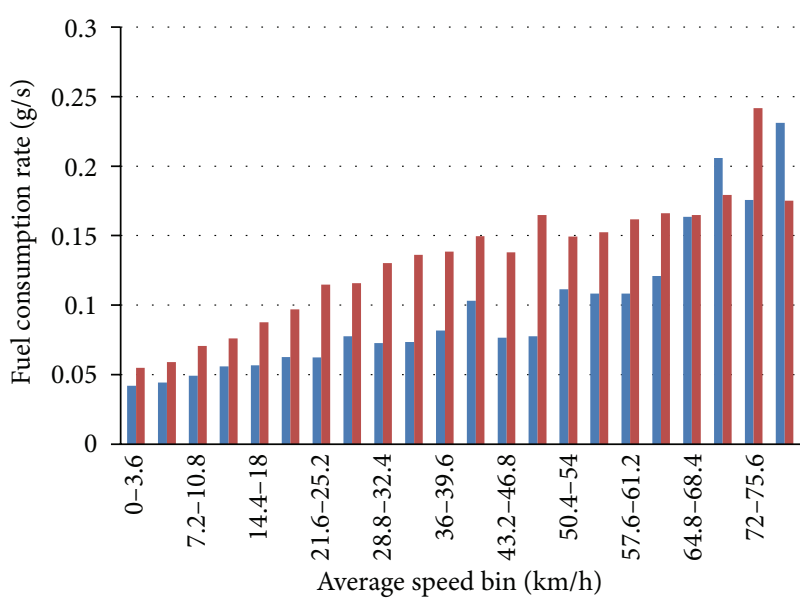

- Light-duty gasoline vehicle

- Heavy-duty diesel vehicle

(e)

FIGURE 2: Emission and fuel consumption prediction values under different average speed-bins (light- and heavy-duty vehicle). 


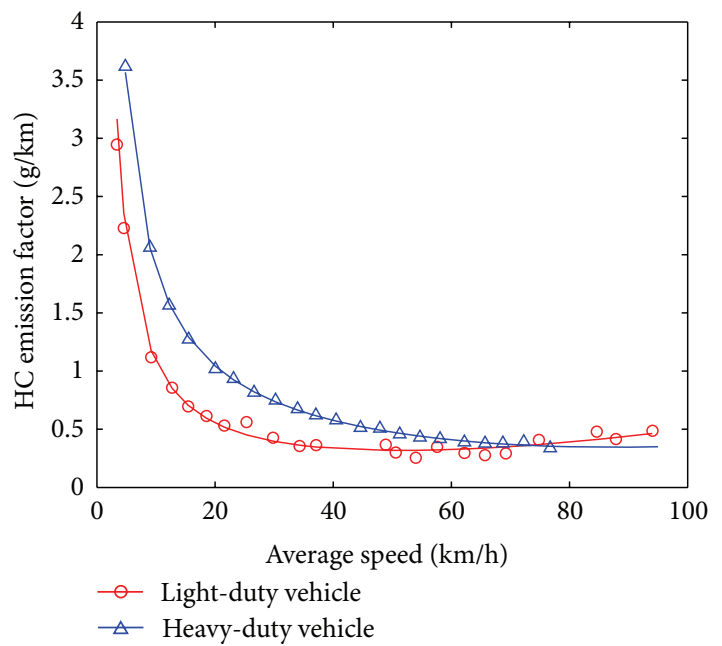

(a)

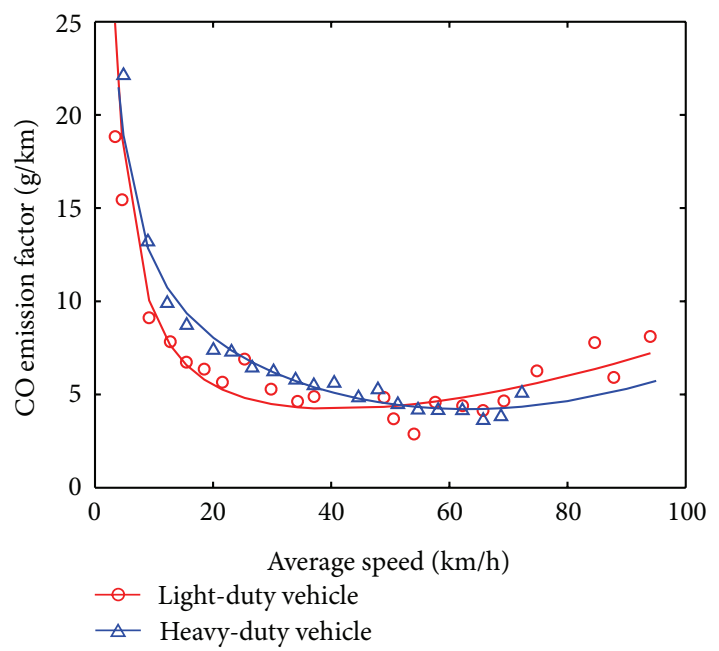

(c)

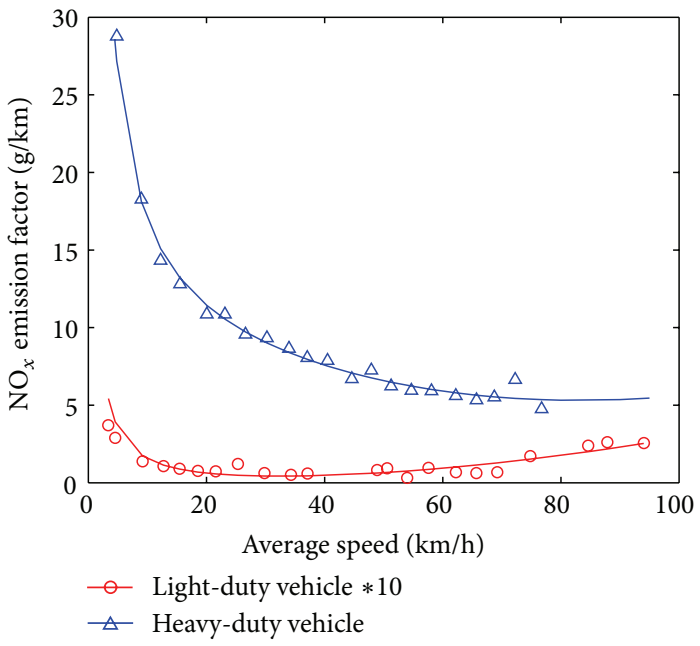

(b)

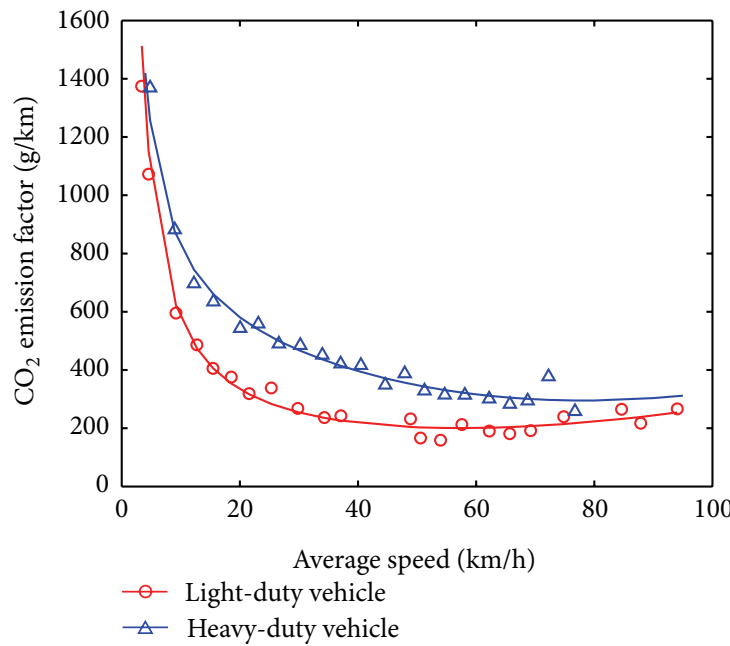

(d)

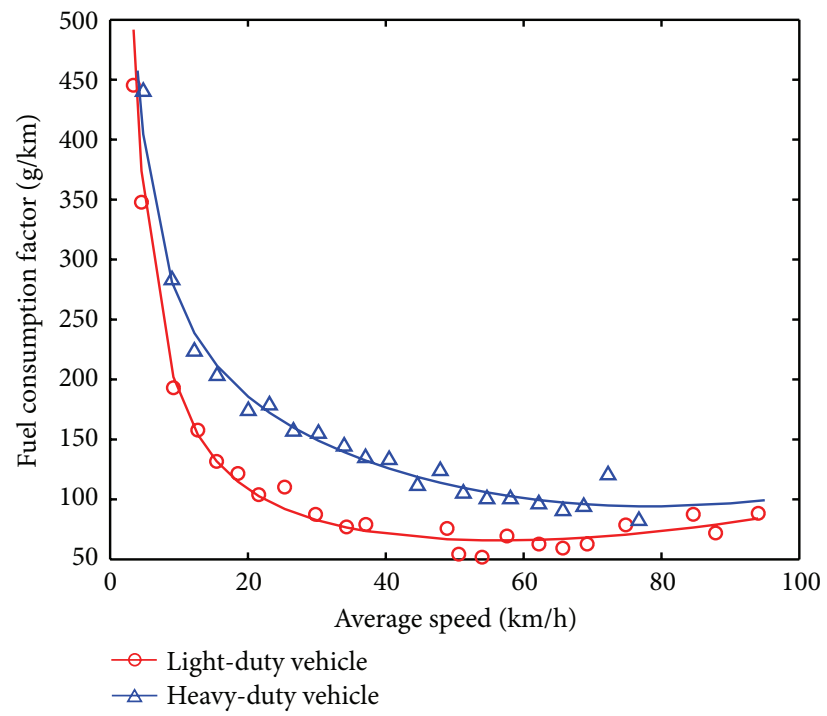

(e)

FIGURE 3: Vehicle emission and fuel consumption curves (light- and heavy-duty vehicle). 


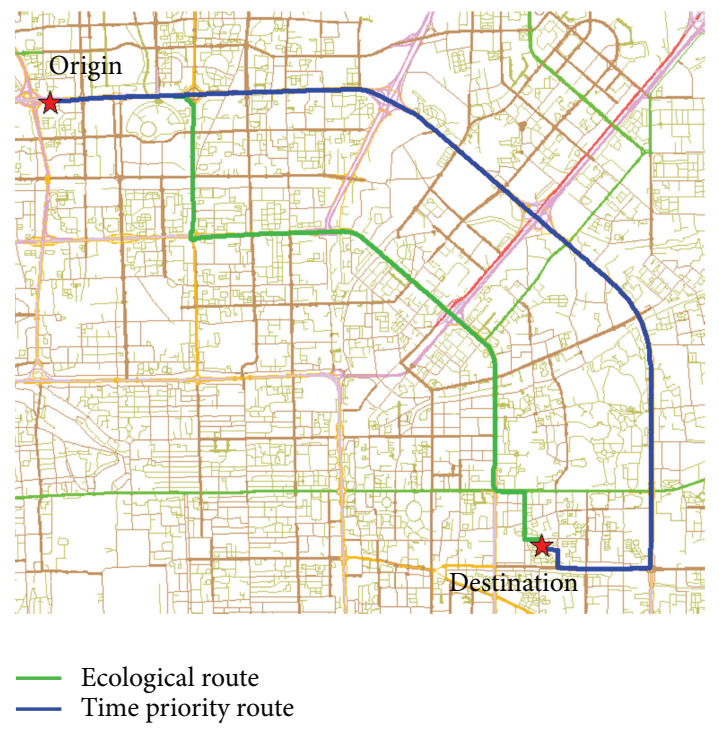

FIgURE 4: Time priority route and ecological route.

\section{Acknowledgment}

This work is supported by National 973 Program of China (no. 2012CB725403).

\section{References}

[1] eCoMove Consortium, ECoMove-Description of Work, eCoMove Consortium, Brussels, Belgium, 2010.

[2] J. D. Vreeswijk, M. K. M. Mahmod, and B. van Arem, "Energy efficient traffic management and control-the eCoMove approach and expected benefits," in Proceedings of the 13th International IEEE Conference on Intelligent Transportation Systems (ITSC '10), pp. 955-961, Madeira, Portugal, September 2010.

[3] M. van der Voort, Design and evaluation of a new fuel-efficiency support tool [Ph.D. thesis], University of Twente, 2001.

[4] E. Ericsson, H. Larsson, and K. Brundell-Freij, "Optimizing route choice for lowest fuel consumption-potential effects of a new driver support tool," Transportation Research C, vol. 14, no. 6, pp. 369-383, 2006.

[5] M. Barth, K. Boriboonsomsin, and A. Vu, "EnvironmentallyFriendly navigation," in Proceedings of the 10th International IEEE Conference on Intelligent Transportation Systems (ITSC '07), pp. 684-689, Seattle, Wash, USA, October 2007.

[6] K. Boriboonsomsin and M. Barth, "ECO-routing navigation system based on multi-source historical and real-time traffic information," in Proceedings of the IEEE Workshop on Emergement Cooperative Technologies in Intelligent Transportation Systems (ICTSC '10), 2010.

[7] M. Barth, C. Malcolm, T. Younglove, and N. Hill, "Recent validation efforts for a comprehensive modal emissions model," Transportation Research Record, no. 1750, pp. 13-23, 2001.

[8] H. Dia, S. Panwai, N. Boongrapue, T. Ton, and N. Smith, "Comparative evaluation of power-based environmental emissions models," in Proceedings of the IEEE Intelligent Transportation Systems Conference (ITSC '06), pp. 1251-1256, Toronto, Canada, September 2006.
[9] U.S. Environmental Protection Agency, "User's guide to MOBILE6. 1 and MOBILE6. 2: mobile source emission factor model," Report No. EPA420-R-03-010, U.S. Environmental Protection Agency, Ann Arbor, Mich, USA, 2003.

[10] California Air Resources Board, EMFAC, 2007 Version 2.30 User's Guide: Calculating Emission Inventories for Vehicles in California, California Air Resources Board, Sacramento, Calif, USA, 2007.

[11] K. Ahn, A. A. Trani, H. Rakha, and M. van Aerde, "Microscopic fuel consumption and emission models," in Proceedings of the 78th Annual Meeting of the Transportation Research Board, Washington, DC, USA, 1999.

[12] M. Barth, F. An, T. Younglove et al., Comprehensive Modal Emission Model (CMEM), Version 2.0 User's Guide, 2000.

[13] J. Koupal, H. Michaels, M. Cumberworth, C. Bailey, and D. Brzezinski, "EPA's plan for MOVES: a comprehensive mobile source emissions model," USEPA Documentation, 2002.

[14] E. K. Nam and R. Giannelli, "Fuel consumption modeling of conventional and advanced technology vehicles in the physical emission rate estimator (PERE)," Draft Report No. EPA420P-05-001, U.S. Environmental Protection Agency, Washington, DC, USA, 2005.

[15] J. Jiménez-Palacios, Understanding and quantifying motor vehicle emissions with vehicle specific power and TILDS remote sensing [Ph.D. thesis], Massachusetts Institute of Technology, 1999.

[16] G. Song, L. Yu, and Z. Wang, "Aggregate fuel consumption model of light-duty vehicles for evaluating effectiveness of traffic management strategies on fuels," Journal of Transportation Engineering, vol. 135, no. 9, pp. 611-618, 2009.

[17] H. Wang, L. Fu, Y. Zhou, and H. Li, "Modelling of the fuel consumption for passenger cars regarding driving characteristics," Transportation Research D, vol. 13, no. 7, pp. 479-482, 2008.

[18] H. Wang and L. Fu, "Developing a high-resolution vehicular emission inventory by integrating an emission model and a traffic model: part 1-modeling fuel consumption and emissions based on speed and vehicle-specific power," Journal of the Air and Waste Management Association, vol. 60, no. 12, pp. 14631470, 2010.

[19] G. Scora, B. Morris, and C. Tran, "Real-time roadway emissions estimation using visual traffic measurements," in Proceedings of the IEEE Forum on Integrated and Sustainable Transportation Systems, 2011.

[20] PeMS Performance Measurement System 10.3. Caltrans, The University of California, PATH, Berkeley, Calif, USA, 2010.

[21] W. Wang, Vehicle's Man-Machine Interaction Safety and Driver Assistance, China Communications Press, Beijing, China, 2012.

[22] H. C. Frey, N. M. Rouphail, H. Zhai, T. L. Farias, and G. A. Gonçalves, "Comparing real-world fuel consumption for diesel- and hydrogen-fueled transit buses and implication for emissions," Transportation Research D, vol. 12, no. 4, pp. 281291, 2007.

[23] P. Andrei, Real world heavy-duty vehicle emission modeling [M.S. thesis], University of West Virginia, 2001.

[24] CN-GB, "Measurement methods of fuel consumption for lightduty vehicles," 2008.

[25] Y. Namikawa, Y. Takai, and N. Ohshiro, Calculation Vase of Motor Vehicle Emission Factors, National Institute for Land and Infrastructure Management, Japan, 2003.

[26] M. André and M. Rapone, "Analysis and modelling of the pollutant emissions from European cars regarding the driving 
characteristics and test cycles," Atmospheric Environment, vol. 43, no. 5, pp. 986-995, 2009.

[27] S. K. Zegeye, B. de Schutter, H. Hellendoorn, and E. Breunesse, "Model-based traffic control for balanced reduction of fuel consumption, emissions, and travel time," in Proceedings of the 12th IFAC Symposium on Transpotaton Systems (CT '09), pp. 149-154, Redondo Beach, Calif, USA, September 2009. 


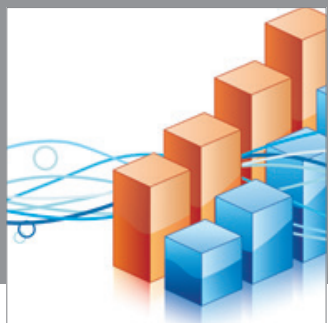

Advances in

Operations Research

mansans

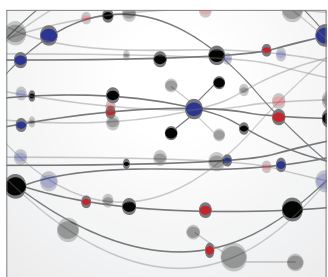

The Scientific World Journal
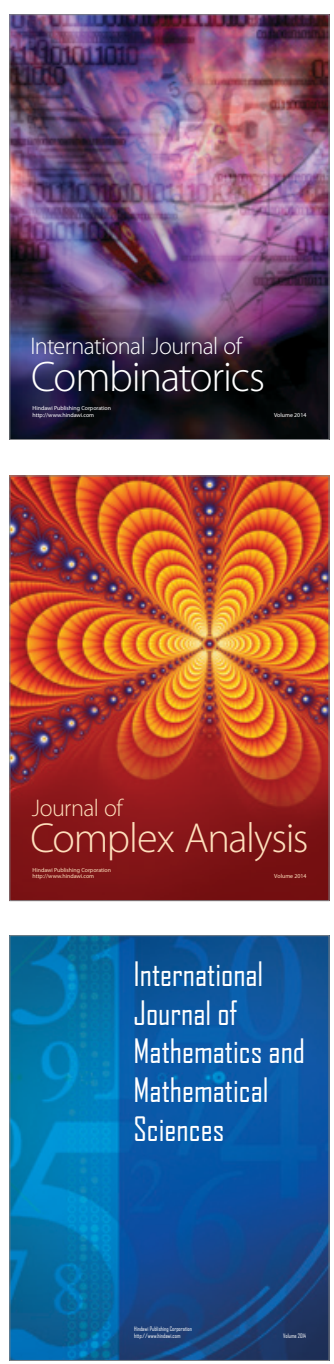
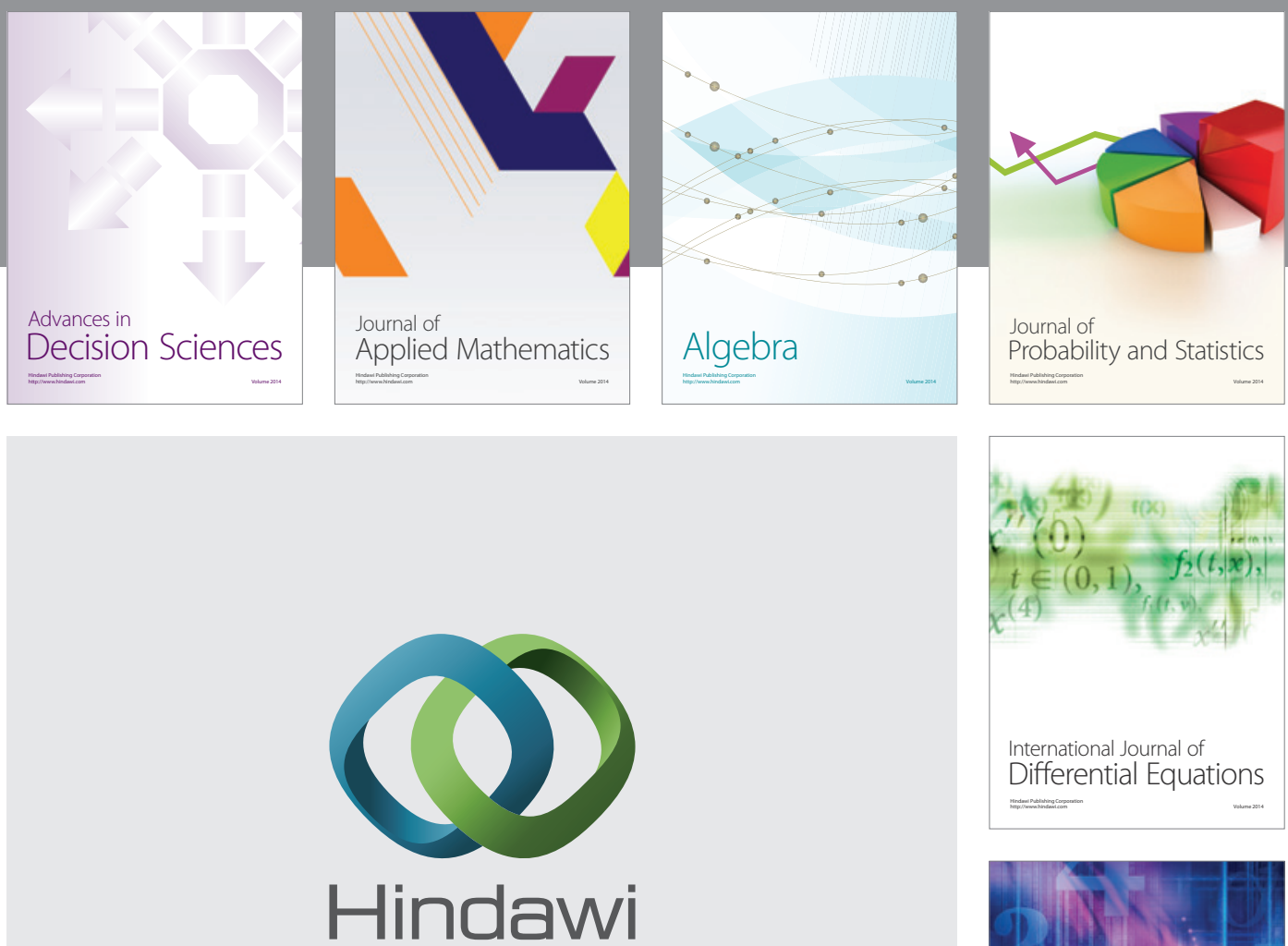

Submit your manuscripts at http://www.hindawi.com
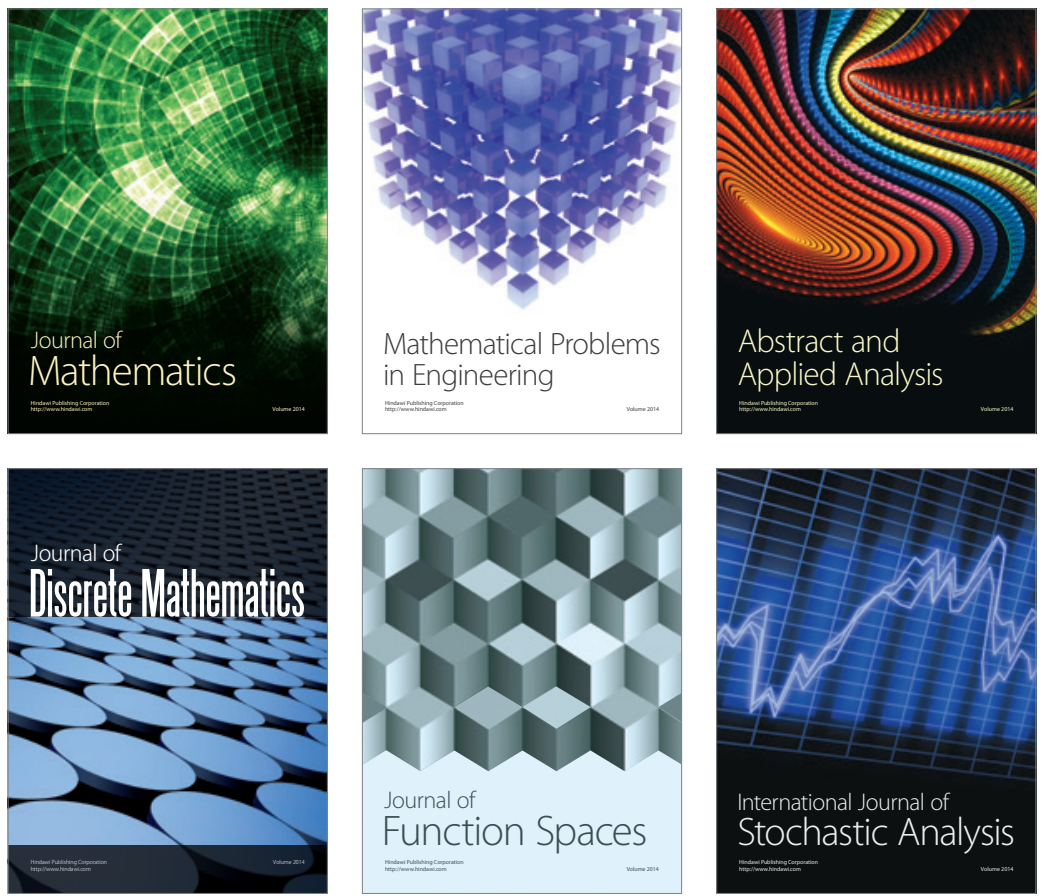

Journal of

Function Spaces

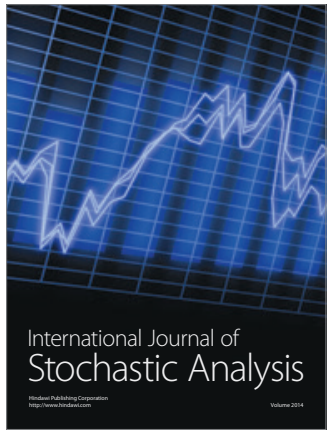

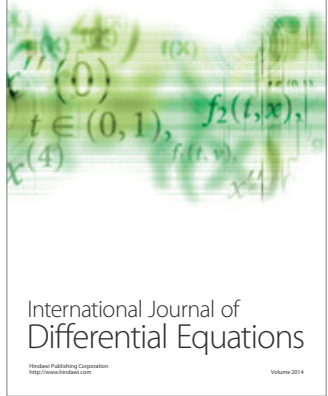
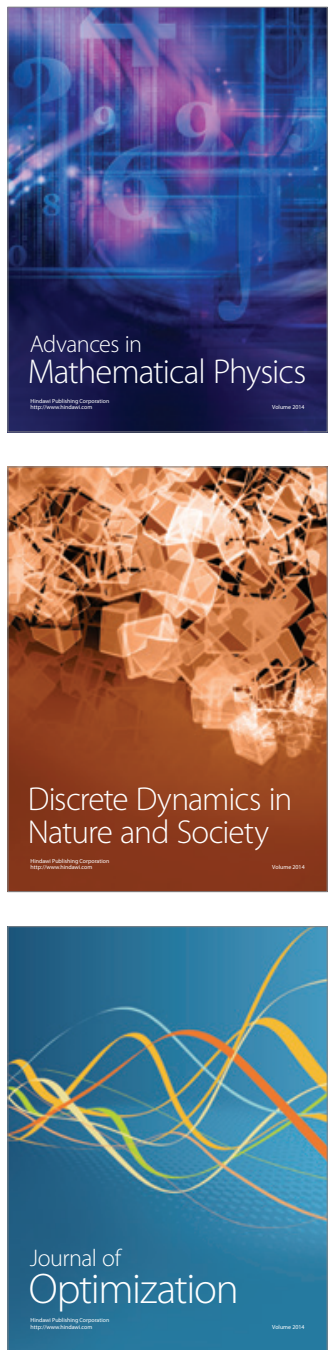